\title{
Incentivo e Promoção do Aleitamento Materno na Consulta de Enfermagem à Criança
}

\author{
Incentive and Promotion of Breastfeeding in the Nursing Consultation of the Child
}

\author{
Priscilla Shirley Siniak dos Anjos Modes ${ }^{1}$ \\ Maria Aparecida Munhoz Gaíva² \\ Caroline Aparecida Coutinho Monteschio ${ }^{3}$
}

1.Enfermeira. Doutoranda pelo Programa de Pós-Graduação em Enfermagem pela Universidade Federal de Mato Grosso. Docente da Disciplina Cuidado Integral à Saúde da Criança e do Adolescente do Curso de Enfermagem do Instituto Ciências da Saúde da Universidade Federal de Mato Grosso, campus Sinop - MT - Brasil. E-mail: priscilladosanjos@yahoo.com.br.

2. Enfermeira. Professora Doutora, do Programa de Pós-Graduação em Enfermagem pela Universidade Federal de Mato Grosso. Cuiabá- MT - Brasil. E-mail: mamgaiva@gmail.com.

3. Enfermeira. Mestre em Enfermagem pelo Programa de Pós-Graduação em Enfermagem pela Universidade Federal de Mato Grosso. Cuiabá- MT - Brasil. E-mail: carolmonteschio@yahoo.com.br. 


\section{ARTIGO ORIGINAL}

\section{Resumo}

O objetivo é analisar a prática assistencial do enfermeiro voltada ao incentivo e promoção do aleitamento materno na consulta de enfermagem à criança. Trata-se de uma pesquisa qualitativa, exploratório-descritiva, com enfermeiros que atuavam em unidades de saúde da família do município de Cuiabá-MT. A coleta de dados foi realizada por meio de observação participante e os dados analisados a partir da técnica de análise de conteúdo temática. Identificou-se, como categoria de análise temática, o incentivo e promoção do aleitamento materno na consulta de enfermagem à criança. Na observação das consultas de puericultura, constatou-se a abordagem sobre os benefícios do aleitamento materno para a criança, importância da sua manutenção exclusiva até os seis meses de vida, comprometimento com as recomendações ministeriais sobre o aleitamento e ações em prol de sua promoção e incentivo. Apesar do trabalho dos enfermeiros em prol da promoção e estímulo do aleitamento materno durante as consultas de puericultura, há que se refletir como esta abordagem tem sido realizada e qual o seu alcance na prática.

Palavras-chave: Aleitamento Materno; Enfermeiros; Atenção Primária à Saúde; Cuidado da Criança.

\section{Abstract}

Objective: to analyze the nurses' practice of nursing promotion and promotion of breastfeeding in the nursing visit to the child. Methodology: qualitative, exploratory-descriptive research, with nurses who worked in family health units in the city of Cuiabá-MT. Data collection was performed through participant observation and data analyzed using the thematic content analysis technique. Results: the thematic analysis category was identified as the incentive and promotion of breastfeeding in the nursing visit to the child. In the observation of child-care consultations, the approach on the benefits of breastfeeding for the child, the importance of maintaining it exclusively up to six months of life, the commitment to the ministerial recommendations on breastfeeding and actions to promote breastfeeding incentive. Conclusions: In spite of the nurses' work in promoting and stimulating breastfeeding during childcare consultations, it is necessary to reflect how this approach has been carried out and how far it has been achieved in practice.

Keywords: breast feeding; nurses; primary health care; child care. 


\section{ARTIGO ORIGINAL}

\section{Introdução}

O aleitamento materno (AM) é a estratégia natural de vínculo ${ }^{(1)}$, afeto, proteção e nutrição para a criança e constitui a mais sensível, completa, econômica e eficaz intervenção para a redução da morbimortalidade infantil, sendo recomendado nos primeiros seis meses de vida da criança de forma exclusiva e complementada até os dois anos de idade ${ }^{2}$. Preconiza-se também que a amamentação ao seio materno seja iniciada na primeira hora de vida da criança, e a partir daí, em livre demanda ${ }^{(2)}$.

Apesar de todas as evidências científicas que demonstram a superioridade e os benefícios da amamentação, dos esforços de organizações nacionais e internacionais, dos programas e políticas brasileiras de incentivo e apoio ao AM, essa prática no país ainda está aquém das recomendações internacionais e do Ministério da Saúde do Brasil(MS) ${ }^{(2-4)}$.

Esse distanciamento entre 0 que é preconizado e o que realmente é encontrado na prática da amamentação foi detectado na última pesquisa sobre a prevalência do AM realizada nas capitais brasileiras e Distrito Federal mostrando que a prevalência do aleitamento materno exclusivo (AME) no país no ano de 2008 em crianças menores de seis meses foi de $41,0 \%$, e Cuiabá foi a capital que apresentou o menor índice do país $(27,1 \%)^{(5)}$.

Os baixos índices de aleitamento materno no país podem ser decorrentes da falta de conhecimentos sólidos dos profissionais de saúde envolvidos na prática da promoção ao aleitamento materno $^{(6)}$, e por fragilidades na rede de apoio à mulher que amamenta, além da falta de estímulo e apoio por parte dos profissionais para a autoeficácia da mulher em praticar a amamentação, fator decisivo para a manutenção do aleitamento materno ${ }^{(3)}$.

Diante do panorama nacional do $A M$ e em nossa realidade, os profissionais de saúde, e em especial o enfermeiro, tem papel fundamental no incentivo e promoção dessa prática. Estas ações devem ocorrer durante o pré-natal, pré-parto, parto, consultas de puerpério e no acompanhamento da criança no primeiro ano de vida. Para tanto, os profissionais precisam estar preparados tecnicamente quanto aos aspectos que envolvem a lactação, acolher mães e familiares e se mostrarem disponíveis para a escuta e esclarecimento de dúvidas. Igualmente, necessitam considerar os fatores emocionais maternos, a cultura familiar, a rede social de apoio à mulher e reconhecê-la como protagonista desse processo, valorizando-a, escutando-a e empoderando- $\mathrm{a}^{(2-7)}$.

0 enfermeiro que atua em atividades sistemáticas e contínuas nos mais diversos espaços de assistência ao público infantil, tem na atenção primária a oportunidade de acompanhar o binômio mãe-filho no primeiro ano de vida, através da consulta de enfermagem, que é um espaço estratégico para desenvolver ações de promoção, proteção, incentivo e apoio ao aleitamento materno, contribuindo para o aumento da autoconfiança materna em amamentar ${ }^{(2-8-9)}$, além da responsabilidade de inserir os familiares e a comunidade neste processo ${ }^{(2-9-10)}$. O enfermeiro pode atuar ainda em outros espaços assistenciais para promover o AM, como o acompanhamento do pré-natal, na maternidade, no puerpério, na primeira semana de saúde integral e no acompanhamento do crescimento e desenvolvimento durante a infância, contribuindo assim, para a redução do aleitamento materno misto e, consequentemente o desmame precoce.

Considerando a importância de se refletir e discutir sobre a assistência no processo de amamentação; o papel dos profissionais de saúde como educadores, apoiadores e promotores do aleitamento materno; a necessidade de capacitação dos profissionais para atender tal demanda e de conhecer como esta prática tem sido desenvolvida nos atendimentos à mãe/criança, este estudo tem como objeto a atuação do enfermeiro no processo de aleitamento materno na consulta à criança, com o intuito de fortalecer as ações desse profissional na estratégia saúde da família (ESF) no que diz respeito à promoção, proteção, incentivo e apoio ao aleitamento materno. Sendo assim, o objetivo do estudo consistiu em analisar a prática assistencial 


\section{ARTIGO ORIGINAL}

do enfermeiro voltada ao incentivo e promoção do aleitamento materno na consulta de enfermagem à criança, buscando responder ao questionamento de como os enfermeiros têm incentivado e promovido o aleitamento materno na consulta de enfermagem à criança nos dois primeiros anos de vida.

\section{Método}

Estudo descritivo exploratório de abordagem qualitativa realizado no município de Cuiabá, estado do Mato Grosso, Brasil, no período de janeiro e fevereiro de 2012. A pesquisa foi desenvolvida em quatro unidades de saúde da família, selecionadas por sorteio, nas quais a consulta de enfermagem à criança era implementada como atividade programática e contínua. Os critérios de inclusão para definir quais consultas de enfermagem seriam observadas foram: consultas com mães ou familiares de crianças com idade entre 0 e 2 anos, cadastrados e em acompanhamento pelas equipes das unidades de saúde da família escolhidas para a pesquisa. A opção por observar consultas de crianças nessa faixa de idade foi por que neste período da infância as consultas são realizadas com intervalos menores, e também por que nessa idade as crianças são mais vulneráveis e demandam maiores cuidados profissionais.

Os dados foram coletados por meio da observação participante nas consultas de enfermagem à criança menor de dois anos nas unidades selecionadas para o estudo. Foram observadas 21 consultas, com duração média aproximada de 30 minutos cada uma. Para auxiliar a observação participante, os diálogos foram captados através de gravação em áudio, para melhor apreender os detalhes dos diálogos entre $o$ enfermeiro e as mães.

A observação participante foi desenvolvida por três pesquisadoras, sendo que uma delas assumiu posição ativa e as outras duas observaram o ambiente, o enfermeiro, a mãe/familiar e a criança. As pesquisadoras receberam treinamento sobre consulta de enfermagem antes da coleta de dados e fizeram uso de um roteiro baseado em avaliação de itens essenciais em um atendimento, a fim de padronizar a observação, que continha os seguintes elementos: anamnese e coleta de dados, exame físico/avaliação da criança, levantamento de problemas, orientações/ações educativas e condutas tomadas.

Como, não havia no município estudado um protocolo específico para a consulta de enfermagem em puericultura e nem a definição de um referencial teórico-metodológico para tal, cada enfermeiro desenvolvia a consulta com a metodologia que julgava mais apropriada ou com aquela que tinha maior domínio.

A escolha por observar consultas de crianças menores de dois anos foi porque neste período da infância as consultas são realizadas com intervalos menores, e também porque nessa faixa de idade as crianças são mais vulneráveis e demandam maiores cuidados profissionais, além da recomendação do AM nesta faixa etária pelo Ministério da Saúde ${ }^{(2)}$. As observações foram transcritas e analisadas, observando-se se os objetivos da pesquisa eram atingidos ou não. Com 21 consultas obteve-se dados suficientes para responder aos objetivos, finalizando desta forma, o trabalho de campo.

Os dados obtidos através da observação foram registrados em diário de campo e as gravações transcritas fidedignamente $\mathrm{e}$ acrescentada aos registros contidos no diário. Para a análise dos dados foi utilizado a técnica de análise de conteúdo na modalidade temática ${ }^{(11)}$, que identificou a categoria temática: incentivo e promoção do aleitamento materno na consulta de enfermagem a criança.

A pesquisa foi desenvolvida de acordo com as normas da Resolução n. 0 466/12 do Conselho Nacional de Saúde e aprovada por Comitê de Ética em Pesquisa, sob o parecer n. ${ }^{\circ} 129 /$ CEPHUJM/2011. Todos os participantes da pesquisa assinaram o Termo de Consentimento Livre e Esclarecido (TCLE) e foi garantido o sigilo e anonimato dos mesmos.

\section{Resultados e Discussão}




\section{ARTIGO ORIGINAL}

\section{Incentivo e promoção do aleitamento materno na consulta de enfermagem à criança}

$\mathrm{Na}$ observação participante das consultas do enfermeiro à criança, constatou-se que as ações de incentivo, promoção e proteção do aleitamento materno são preocupações deste profissional, em especial, nas crianças menores de seis meses, com destaque aos benefícios dessa prática para o bebê, conforme destacado nos recortes do diário de campo:

Enfermeiro: [...] vamos dizer assim, livre demanda, que nos primeiros seis meses é única e exclusivamente o leite materno. Não há necessidade de outra coisa, de outro alimento, a não ser o leite materno porque ele tem nutrientes essenciais $e$ importantes para alimentar a tua filha. Desde água, os nutrientes, vitaminas. Você tem passado as suas defesas através do leite, através dos anticorpos, tudo isso ela absorve e outras substâncias importantes para o desenvolvimento e crescimento dela. [...]. (Diário de campo, consulta 15).

Enfermeira: [...] o aleitamento materno é o mais importante nos primeiros meses de vida da criança e é o que a gente mais pega no pé da mãe, é o que mais agente orienta. A mãe tem que dar de mamar para a criança. É o que fortalece, é o que nutre, é o que faz a criança se desenvolver [...]. (Diário de campo, consulta 8).

O leite materno humano é a fonte ideal de nutrição, permitindo que todo o potencial genético inerente possa ser atingido. Isso se deve ao fato de a composição do leite materno garantir a quantidade necessária de água, carboidratos, lipídeos e proteínas para o desenvolvimento adequado dos lactentes ${ }^{(1)}$, contribuindo para a promoção e proteção da saúde infantil ${ }^{(12)}$. Ademais é prático ${ }^{(1-12)}$, isento de bactérias e contém fatores imunológicos que protegerão a criança ${ }^{(1)}$.

Embora tenha sido observado durante as consultas que os enfermeiros tenham dado maior ênfase aos benefícios do leite materno para o bebê, sabe-se que além dos benefícios orgânicos do leite materno, o mesmo possui um grande impacto na saúde mental, emocional, psíquica e cognitiva da criança e de sua mãe, por permitir o fortalecimento do vínculo afetivo e a interação entre o binômio, consolidação de sentimentos de segurança, proteção, laços afetivos e bem-estar ${ }^{(1-13)}$, que são elementos importantes na promoção do crescimento e desenvolvimento adequados ${ }^{(1)}$, além de contribuir para o aumento da inteligência e aprendizado $^{(1-14)}$.

Contudo há também o envolvimento das questões socioeconômicas e culturais, pois esta prática não onera financeiramente a família ${ }^{(2-15)}$, é prática $^{(12-15)}$, estando o leite pronto, sem risco de estragar, na temperatura ideal e pode ser oferecido a qualquer momento e em qualquer lugar, sem a exigência do preparo e higienização ${ }^{(12)}$.

Outro aspecto relevante a ser trabalhado pelos profissionais quanto aos benefícios do AM está relacionado ao desenvolvimento e fortalecimento de vínculo do binômio mãe-bebê, aspecto este que não foi observado durante as consultas de puericultura analisadas. A prática de amamentar é essencial para o desenvolvimento afetivo mãe/filho, proporcionando uma ligação emocional muito forte e que servirá como base para futuros relacionamentos de confiança com outras pessoas ${ }^{(12)}$.

Acrescidos a estes benefícios, tem-se a questão da superioridade do leite materno sobre os leites de outras espécies, pois evita as mortes infantis, infecções respiratórias e diarreias ${ }^{(2-4-16)}$; diminui os riscos de alergias, hipertensão(2-16), diabetes $^{(1-2-14)}$ e colesterol alto ${ }^{(2)}$; reduz a chance de obesidade ${ }^{(2-14)}$; melhora o crescimento pônderoestatural ${ }^{(1)}$; facilita o desenvolvimento da cavidade bucal $^{(2)}$; previne cáries ${ }^{(4)} \mathrm{e}$; para as mães, protege 
contra o câncer de mama, útero e ovário ${ }^{(2)}$; evita nova gravidez ${ }^{(2-13)}$; protege contra o diabetes gestacional e $o$ aparecimento de anemia no período puerperal ${ }^{(1)}$; auxilia na perda de peso pósparto $^{(1-13)} \mathrm{e}$; previne a hemorragia no pós-parto ${ }^{(13)}$.

As vantagens da amamentação para o bebê e para a mãe necessitam ser divulgadas e reforçadas durante as consultas para que haja amplo acesso a este conhecimento, o que não ocorre em muitas unidades de saúde do país, conforme evidenciou estudo realizado na Paraíba com 57 mães de crianças com até 6 meses de idade, que identificou a partir dos relatos das mães entrevistadas, que o conhecimento sobre os benefícios do aleitamento materno era predominantemente voltado à criança, sendo que a maioria delas desconhecia os benefícios maternos, mostrando a necessidade desta temática ser melhor trabalhada junto à população, já que pode ser uma motivação a mais para que a mulher fortaleça sua decisão por amamentar $^{(13)}$.

Por outro lado, muitas mulheres já possuem o conhecimento sobre os benefícios do AM para si próprias, como mostram os resultados do estudo realizado em município da Bahia, em que as mulheres se reconheciam como beneficiárias da amamentação, relatando que o ato de amamentar previne nova gravidez e câncer, além de ser prático ${ }^{(12)}$, diferentemente do observado no presente estudo, em que os enfermeiros focaram suas orientações sobre o AM apenas nos benefícios para o bebê.

Diante dos evidentes benefícios do AM que transcendem o valor biológico apenas à criança, das recomendações internacionais e nacionais e, das políticas públicas brasileiras voltadas à sua proteção, promoção e apoio, o enfermeiro deve encorajar esta prática entre as mães, orientando-as quanto a importância de se oferecer somente o leite materno nos primeiros seis meses de vida da criança, sem necessidade de complementação, conforme retrata alguns recortes de observação:

Enfermeiro: [...] está mamando de quanto em quanto tempo? Mãe: é toda hora.

Enfermeiro: (risos) você está

\author{
dando algum outro alimento \\ para ele? \\ Mãe: só leite. \\ Enfermeiro: nem aguinha? Mas \\ e o chazinho? \\ Mãe: nem cólica ele está tendo \\ mais. \\ Enfermeiro: e aguinha? \\ Mãe: ainda não. \\ Enfermeiro: então, está bom! Tá \\ certinho! (elogia a mãe por \\ estar ofertando somente o leite \\ materno para a criança). \\ Mãe: se ele está com sede, eu \\ dou o leite. \\ Enfermeiro: tem que lembrar \\ disso, ele não precisa de nada \\ até seis meses. Quando tiver \\ chegando nos seis meses você já \\ vai voltar aqui pra gente pode \\ começar a conversar sobre o \\ que vai dar (fala a respeito da \\ alimentação) [...] (Diário de \\ campo, consulta 9).
}

Enfermeira: [...] É porque está com três meses, então a gente ainda tem mais três meses para lutar pelo aleitamento exclusivo $e$ tem até dois anos para você continuar amamentando ela no peito [...] (Diário de campo, consulta 6).

0 enfermeiro deve reforçar constantemente que não é necessário ofertar nenhum outro alimento além do $A M$ à criança, incluindo chás, água ou outros líquidos ou sólidos. Ofertar tais complementos pode ser uma prática cultural e familiar prejudicial à saúde da criança, uma vez que substitui o volume de leite materno que é mais nutritivo ${ }^{(2-17)}$, podendo acarretar riscos e doenças potenciais para esta criança.

Assim, o profissional deve explicar à mãe que a introdução destes líquidos está associada ao uso de mamadeira e ao desmame precoce e ao 


\section{ARTIGO ORIGINAL}

aumento da morbimortalidade infantil por diarreia aguda $^{(2-16)}$. Portanto, faz-se necessário uma atuação qualificada dos profissionais de saúde para a promoção do aleitamento materno ${ }^{(18)}$, afim de prevenir esses quadros de morbimortalidade.

Além de orientar as mulheres sobre a importância do aleitamento materno exclusivo nos primeiros seis meses de vida da criança, dos seus benefícios e de reforçar quanto a não utilização de outros líquidos no aleitamento exclusivo, é relevante o enfermeiro se atentar para os valores familiares imbricados no processo de amamentação, uma vez que estes podem influenciar positiva ou negativamente na amamentação, conforme apontam os recortes do diário de campo a seguir:

Enfermeira: [...] dá água, chá? Mãe: só água porque diz que dá sede na criança (enfermeira interrompe a fala da mãe).

Enfermeira: não dá sede, quem que foi que te falou isso? (voz autoritária)

Mãe: minha mãe. [...](Diário de campo, consulta 1).

\section{Enfermeira: [...] e a amamentação dela, aquele dia a gente conversou, você está tendo bastante leite? Está segura com a amamentação? Mãe: estou. \\ Enfermeira: os outros filhos você amamentou? \\ Mãe: não, a $T$, não (nome da filha mais velha). Não tive leite. [...] (Diário de campo, consulta 2).}

A amamentação é uma prática que envolve relação de ensino e aprendizado entre as gerações e está sujeita a uma série de condicionantes culturais, o que significa que as experiências anteriores de membros da família podem vir a interferir neste processo. Nesse sentido, os significados construídos pelas gerações mais novas no processo de amamentar dependem, em parte, dos significados transmitidos por suas mães e avós maternas para além das mudanças sociais, econômicas e culturais do meio onde vivem, desencadeando continuidades e descontinuidades nas práticas e representações relacionadas ao fenômeno da amamentação ${ }^{(4-19)}$.

Dessa forma, muitas mães acatam as orientações das avós por entender que as mesmas compartilham suas experiências pessoais de cuidado e as reproduzem com o desejo expresso de acertar e de dar o melhor de si, no intuito de ajudar as novas mães.

As observações mostraram ainda que o enfermeiro repassa suas orientações sustentadas em conhecimento científico e em seu modo pessoal e profissional de ver o AM, e muitas vezes por se surpreender com as respostas culturais das mulheres, acaba passando informações equivocadas, como descrito acima no relato da consulta 1 , em que o enfermeiro afirmou que a criança não tem sede e por isso não necessita de água. O que na realidade deveria ter sido dito é que $\mathrm{o}$ bebê sente sede, porém não existe a necessidade de se ofertar água, uma vez que o leite materno contém em sua composição este ingrediente e pode saciar sua sede.

Neste caso, o profissional desconsiderou e não agregou as informações trazidas pela mãe em suas orientações, além de não aprofundar o conhecimento prévio da mesma e de sua família sobre a prática do AM e os aspectos socioculturais envolvidos, com prejuízo para o atendimento integral a esta clientela.

Assim, apesar da importância do conhecimento técnico do enfermeiro sobre o aleitamento, é importante avançar na abordagem durante as consultas, já que ele como agente formador de opinião, deve sensibilizar tanto a mulher/mãe como seus familiares sobre a importância dessa prática, suas vantagens e benefícios, desmistificando mitos e tabus, levando em consideração o contexto sociocultural no qual estas mães estão inseridas ${ }^{(12)}$.

O enfermeiro necessita levar em consideração na abordagem individual de cada 


\section{ARTIGO ORIGINAL}

mulher, que a família tem sua própria maneira de conduzir a prática do aleitamento. Assim é preciso traçar estratégias que visem conciliar o saber científico com o saber popular, para melhor apoiar a prática do aleitamento materno exclusivo(15), evitando impor normas e regras que não contemplam a realidade da nutriz, gerando medo e insegurança e dificultando a adesão à prática da amamentação.

Ressalta-se que em todas as consultas em que $O A M$ foi abordado, os enfermeiros demonstraram conhecimentos técnicos, habilidades e segurança no manejo clínico da amamentação, além de repassar para a mãe as recomendações ministeriais sobre esta prática. No entanto, é preciso ir além do conhecimento técnico da lactação, desenvolvendo um olhar atento, agregador e abrangente sobre os aspectos emocionais, culturais do $A M$ e a rede social de apoio à mulher ${ }^{(2)}$, além de apoia-las frente às dificuldades dessa prática, suprindo as carências de informação e respeitando a postura apresentada pela mulher.

Nesta perspectiva, os profissionais de saúde necessitam considerar a amamentação mais do que um ato puramente instintivo e biológico e sim como um processo biopsicossocial, dinâmico e relacional, para tal, devem desenvolver habilidades tanto teóricas como práticas ${ }^{(10-15)}$.

No que concerne à influência e o apoio da família no processo da amamentação, pode-se citar:

Enfermeira: [...] está tendo problema para amamentar? (a mãe responde com a cabeça negativamente). Então nada de mamadeira, nada de água, nada de chá (afirmativa). Enfermeira: Quem te influencia com relação a amamentação da criança e os cuidados?

Mãe: A mãe olha para a tia que está em pé com a criança no colo e uma sorri para outra e a e mãe diz: - minha tia la enfermeira olha para tia $e$ continua a conversa).

Enfermeira: é você que está influenciando? Então quais são as recomendações? Eu vou passar para $S$. (nome da mãe) $e$ vou passar para você também (tia), para vocês seguirem certinho o que é preconizado para cuidar de uma criança recém-nascida. Então assim, os familiares ajudam muito dando apoio para mãe, porque ela está sofrendo, porque está tendo rachaduras, porque é a primeira vez que ela é mãe então ela conta com a familia. Interrompe o raciocínio e olha para tia e lhe dirige a pergunta, você já é mãe? (ela responde afirmativamente com a cabeça). Então assim. Ah! Vamos dá água porque está com sede. Vão dá chá porque está com cólica, criança não precisa de muita manipulação, quanto menos manipulação da criança melhor. Quanto menos você interferir no que é normal da criança melhor [...] (Diário de campo, consulta 8).

Como podemos observar neste recorte do diário de campo, a prática da amamentação é fortemente influenciada pelo contexto no qual a nutriz se insere. Sendo assim, para a amamentação ser bem-sucedida, a mãe necessita constantemente ser incentivada e receber suporte, não só por parte dos profissionais de saúde, mas também da sua família e da comunidade. Não basta apenas que a mulher opte por amamentar, ela precisa estar inserida em um ambiente que a apoie em sua escolha. A opinião e o incentivo das pessoas que a cercam, sobretudo os maridos/companheiros, as avós da criança e outras pessoas significativas para a mãe são de extrema importância ${ }^{(2-19)}$.

Diante disto, verifica-se a importância do 
enfermeiro na construção de valores sobre o AM, junto à mãe, sua família, grupos e comunidade, valorizando a sua rede de apoio e incluindo-a neste cuidado. Assim, uma forma de ampliar e intensificar a promoção do AME é ir além dos aspectos técnicos da amamentação, é conhecer o contexto familiar, utilizando-se da participação da família, seus valores, conceitos e entendimento, para assim implementar as ações educativas e fortalecer a ambiência de tal prática.

Em relação as ações de promoção, apoio e proteção ao aleitamento materno, o Brasil tem avançado na proposição de ações e estratégias, a exemplo da Iniciativa Unidade Básica Amiga da Amamentação (IUBAAM), lançada pela Secretaria de Saúde do Rio de Janeiro no ano de 1999. Destaca-se que até o momento da coleta de dados da presente pesquisa não havia nenhuma unidade de saúde credenciada como amiga da amamentação no município de Cuiabá, MT.

Ainda na perspectiva de incentivar a promoção do aleitamento materno na Atenção Básica, o Ministério da Saúde propôs em 2008, a estratégia Rede Amamenta Brasil, que objetivou qualificar o processo de trabalho dos profissionais de atenção básica e, a partir disso, incentivar o aleitamento materno e a alimentação saudável para crianças menores de dois anos no âmbito do Sistema Único de Saúde ${ }^{(20)}$

Uma pesquisa avaliativa sobre o impacto da estratégia da Rede Amamenta Brasil sobre a situação do aleitamento materno em municípios brasileiros identificou o aumento da prevalência do AME em unidades básicas de saúde com maior grau de implantação da estratégia, mostrando a influência favorável de ações de promoção, proteção e apoio ao aleitamento materno, como os grupos de apoio à amamentação e as orientações sobre seu manejo realizadas em unidade básica de saúde ${ }^{(21) .}$

Estes resultados evidenciam a importância das orientações sobre aleitamento materno oferecidas pelos enfermeiros na consulta de puericultura e a necessidade de que as ações educativas individuais e/ou coletivas sejam desenvolvidas já no contexto da assistência pré- natal e mantidas nas consultas à criança nos primeiros meses de vida, para manutenção da amamentação exclusiva e de melhores taxas de prevalência de aleitamento materno nos municípios.

Para auxiliar os enfermeiros nas ações educativas das consultas de enfermagem à criança, faz-se necessário também a inclusão de inovações na comunicação entre profissional de saúde e mães, por meio da implementação da utilização de tecnologias em saúde na promoção do aleitamento materno, a exemplo de álbum seriado e manual educativo, que são tecnologias ilustradas e a musicalização, que é uma tecnologia assistida, afim de viabilizar a inclusão social, construir o conhecimento, reforçar o conhecimento para utilizar em outros espaços que não somente a unidade de saúde e, orientar de forma estruturada, gerando desta forma, impactos positivos no aleitamento materno ${ }^{(22)}$.

Apesar de não ser foco do presente artigo, cabe ressaltar que algumas mães que participaram da presente pesquisa não conseguiram amamentar exclusivamente nos seis primeiros meses ou tiveram desmame precoce, situação essa que já foi discutida em artigo já publicado anteriormente ${ }^{(23)}$.

\section{Conclusão}

Conclui-se que, neste estudo, os enfermeiros abordaram aspectos importantes do aleitamento materno às mães durante a consulta de enfermagem à criança, a exemplo dos benefícios desta prática para os bebês e a importância da sua manutenção exclusiva até os seis meses de vida e complementado até os dois anos. Os resultados evidenciaram também, o comprometimento e responsabilidade deste profissional em repassar às mães as recomendações e preceitos ministeriais sobre a prática do aleitamento materno.

Todavia, é preciso que o enfermeiro valorize os familiares envolvidos, as experiências, o contexto sociocultural e o conhecimento prévio das mães sobre a prática da amamentação, incentive a participação dos familiares nesse processo, aconselhe sobre os benefícios do aleitamento para 


\section{ARTIGO ORIGINAL}

a saúde materna e sociedade, além de considerar o contexto familiar e as fontes de apoio para esta prática.

Apesar do trabalho dos enfermeiros em prol da promoção e estímulo do aleitamento materno durante as consultas de puericultura, há que se refletir como esta abordagem tem sido realizada e qual o seu alcance na prática. Assim, abre-se espaços para estudos com outras perspectivas quanto à efetividade da consulta de puericultura para o sucesso da amamentação.

Uma limitação da pesquisa foi retratar apenas a perspectiva dos pesquisadores sobre o processo de aleitamento materno. Assim, sugeremse mais pesquisas sobre a temática que abordem a visão dos enfermeiros e das mães/lactantes. No entanto, os resultados aqui apresentados poderão sensibilizar os enfermeiros que desenvolvem ações no pré-natal, puerpério e acompanhamento de puericultura sobre a importância das ações de proteção, apoio, promoção e incentivo ao aleitamento materno, além de oferecer elementos para a melhoria da qualidade dessas ações.

\section{Referências}

1. Nunes LM. Importância do aleitamento materno na atualidade. Boletim Científico de Pediatria, 2015; 4(3): 55-8.

2. Ministério da Saúde (BR). Secretaria de Atenção à Saúde. Departamento de Atenção Básica. Saúde da criança: aleitamento materno e alimentação complementar. 2. ed. Brasília: Ministério da Saúde [Internet]. 2015 [acesso em 08 dez 2017]; p.184. Disponível em: http://bvsms.saude.gov.br/bvs/publicacoes/saude _crianca_aleitamento_materno_cab23.pdf.

3. Sousa F, Claro ML, Sousa AL, Lima LHO, Santana AGS. Avanços e desafios do aleitamento materno no Brasil: uma revisão integrativa. Rev Bras Promoç Saúde, Fortaleza [Internet]. 2015 JulSet [acesso 08 Dez 2017]; 28(3): 434-442. Disponível em: http://periodicos.unifor.br/RBPS/article/view/3881 /pdf.

4. Uema RTB, Souza SNDH, Mello DF, Capellini VK. Prevalência e fatores associados ao aleitamento materno no brasil entre os anos 1998 e 2013: revisão sistemática. Semina: Ciências Biológicas e da Saúde, Londrina [Internet]. 2015 Ago [acesso 08 Dez 2017]; 36(1), supl: 349-62. Disponível em: http://www.uel.br/revistas/uel/index.php/seminab io/article/view/19269/16935.

5. Ministério da Saúde (BR). Secretaria de Atenção à Saúde. Departamento de Ações Programáticas e Estratégias. Pesquisa de Prevalência de Aleitamento Materno em Municípios Brasileiros. Situação do Aleitamento Materno em 227 municípios brasileiros. Brasília DF: Ministério da Saúde [Internet]. 2010 [acesso em 08 dez 2017]; p.63. Disponível em: http://www.redeblh.fiocruz.br/media/pamuni.pdf.

6. Passos, LP; Pinho $L$ de. Profissionais de saúde na promoção ao aleitamento materno: revisão integrativa. Rev enferm UFPE on line., Recife [Internet]. 2016 Abr [acesso 08 dez 2017]; 10(Supl. 3):1507-16. Disponível em: https://periodicos.ufpe.br/revistas/revistaenferma gem/article/view/11092/12545.

7. Cunha ÉC, Siqueira $\mathrm{HCH}$. Aleitamento Materno: Contribuições da Enfermagem. Ensaios Cienc., Cienc. Biol. Agrar. Saúde [Internet]. 2016 [acesso 08 dez 2017]; 20(2): p. 86-92. Disponível em:

http://www.pgsskroton.com.br/seer/index.php/en saioeciencia/article/viewFile/4047/3273.

8. Rito RVVF, Castro IRR, Trajano AJP, Gomes MASM, Bernal RTI. Breastfeeding-Friendly Primary Care Initiative: Degree of implementation in a Brazilian metropolis. Rev. Nutr., Campinas [Internet]. 2013 Jul-Ago [acesso em 08 dez 2017]: 26(4):385-95. Disponível em: http://www.scielo.br/pdf/rn/v26n4/a01v26n4.pdf. 


\section{ARTIGO ORIGINAL}

9. Ministério da Saúde (BR). Secretaria de Atenção à Saúde. Departamento de Ações Programáticas Estratégicas. Área Técnica da Saúde da Criança e Aleitamento Materno. Agenda de Compromissos para Saúde Integral da Criança e Redução da Mortalidade Infantil. 1st ed. 2. impressão. Brasília, DF: Ministério da Saúde. 2005; $80 \mathrm{p}$.

10. Almeida M, Luz SAB, Ued FV. Apoio ao aleitamento materno pelos profissionais de saúde: revisão integrativa da literatura. Rev Paul Pediatr [Internet]. 2015 [acesso $08 \mathrm{dez}$ 2017];33(3):355$362 . \quad$ Disponível em: http://www.scielo.br/pdf/rpp/v33n3/0103-0582rpp-33-03-0355.pdf.

11. Bardin, L. Análise de Conteúdo. 6. ed. Lisboa: Edições 70 Ltda; 2011.

12. Dias RB, Araújo RT de, Mota TN et al. Meaning of breastfeeding in the collective imaginary of women/mothers who breastfed. Rev enferm UFPE on line. 2015 Dez; 9(12):1102-9.

13. Macedo MDS, Torquato IMB, Trigueiro JVS, Albuquerque $A M$, Pinto $M B$, Nogueira $M F$. Aleitamento materno: identificando a prática, benefícios e os fatores de risco para o desmame precoce. Rev enferm UFPE on line., Recife, 2015; 9(supl. 1):414-23.

14. Garcia, Leila Posenato. The Lancet: série sobre amamentação. Epidemiol. Serv. Saúde, Brasília [Internet]. 2016 Jan-Mar [acesso $08 \mathrm{dez}$ 2017]; 25(1):203-04. Disponível em: http://www.scielo.br/pdf/ress/v25n1/2237-9622ress-25-01-00203.pdf.

15. Dos-Santos EM, Agra, GFA. "Só o leite materno!" - significados de nutrizes sobre o aleitamento materno exclusivo. Semina: Ciências Biológicas e da Saúde, Londrina [Internet]. 2016 Jul-Dez [acesso 08 dez 2017]; 37(2): 93-106. Disponível

em: http://www.uel.br/revistas/uel/index.php/seminab io/article/view/23532/20329.

16. Santos FS, Santos LH, Saldan PC, Santos FCS, Leite AM, Mello DF. Aleitamento materno e diarreia aguda entre crianças cadastradas na estratégia saúde da família. Texto Contexto Enferm [Internet]. 2016 [acesso 08 dez 2017]; 25(1): 01-8; e0220015. Disponível em: http://www.scielo.br/pdf/tce/v25n1/pt_01040707-tce-25-01-0220015.pdf.

17. Ministério da Saúde (BR). Secretaria de Atenção à Saúde. Departamento de Atenção Básica. Dez passos para uma alimentação saudável: guia alimentar para crianças menores de dois anos: um guia para o profissional da saúde na atenção básica. 2. ed. 2 reimpr. Brasília: Ministério da Saúde [Internet]. 2013 [acesso $08 \mathrm{dez}$ 2017]; p.72. Disponível em: http://bvsms.saude.gov.br/bvs/publicacoes/dez_p assos_alimentacao_saudavel_guia.pdf.

18. Vargas GS, Alves VH, Rodrigues DP, Branco MBLR, Souza RMP, Guerra JVV. Atuação dos profissionais de saúde da estratégia saúde da família: promoção da prática do aleitamento materno. Revista Baiana de Enfermagem, Salvador [Internet]. 2016 Abr-Jun [acesso 08 dez 2017]; 30(2): 1-9. Disponível em: https://portalseer.ufba.br/index.php/enfermagem/ article/view/14848/pdf_32.

19. Moreira MA, Nascimento ER, Paiva MS. Representações sociais de mulheres de três gerações sobre práticas de amamentação. Texto contexto - enferm. Florianópolis [Internet]. 2013, Abr-Jun [acesso 08 dez 2017]; 22(2): 432-41. Disponível em: http://www.scielo.br/scielo.php?script=sci_arttext \&pid=S0104-07072013000200020.

20. Ministério da Saúde (BR). Secretaria de Atenção à Saúde. Departamento de Ações Programáticas Estratégicas. Análise de implantação da Rede Amamenta Brasil: relatório de pesquisa. 


\section{ARTIGO ORIGINAL}

Brasília: Ministério da Saúde [Internet]. 2013 [acesso 08 dez 2017]; p.82. Disponível em: http://bvsms.saude.gov.br/bvs/publicacoes/analise _implantacao_amamenta_brasil_relatorio.pdf.

21. Venâncio, S. I.; Martins, M. C. N.; Sanches, M. T. C.; Almeida, H.; Rios, G. S.; Frias, P. G. Análise de implantação da Rede Amamenta Brasil: desafios e perspectivas da promoção do aleitamento materno na atenção básica. Cad Saúde Pública [Internet]. 2013 Nov [acesso 08 dez 2017]; 29(11):2261-74. Disponível em: http://www.scielo.br/pdf/csp/v29n11/13.pdf.

22. Souza EFC, Carmona EV, Lopes MHBM, Shimo AKK. Tecnologia em aleitamento materno: revisão integrativa da literatura. Revista Enfermagem Atual. 2017; 83:111-15.

23. Monteschio CAC, Gaíva MAM, Moreira MDS. The nurse faced with early weaning in child nursing consultations. Rev Bras Enferm. [Internet] 2015 [acesso 20 mar 2018]; 68(5):587-93. Disponível em: http://dx.doi.org/10.1590/00347167.2015680515i. 